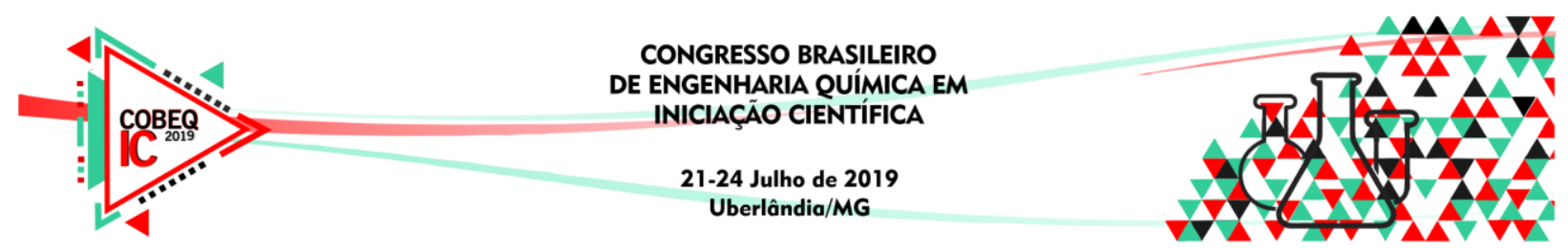

\title{
ANÁLISE DE ABSORÇÃo DE ÁGUA EM COMPÓSITOS DE ÓLEO DE MAMONA REFORÇADO COM BAGAÇO DE CANA DE AÇÚCAR.
}

\author{
V. B. DA SILVA ${ }^{1}$, Y. M. FEITOSA ${ }^{2}$, G. DE S. MARADINI ${ }^{1}$, S. M. DE ALMEIDA ${ }^{2}$, M. P. \\ OLIVEIRA $^{3}$
}

\author{
${ }^{1}$ Universidade Federal do Espírito Santo, Programa de Pós-Graduação em Engenharia \\ Química \\ ${ }^{2}$ Universidade Federal do Espírito Santo, Faculdade de Engenharia Química \\ ${ }^{3}$ Universidade Federal do Espírito Santo, Departamento de Engenharia Madeireira \\ E-mail para contato: yara.martins.f@ hotmail.com
}

\begin{abstract}
RESUMO - Existe uma crescente busca por materiais ambientalmente corretos, e que agridam menos o meio ambiente, neste contexto encontram-se os compósitos poliméricos reforçados com fibras naturais. Neste trabalho buscou-se aliar as fibras naturais de cana de açúcar com uma resina proveniente do óleo de mamona, a poliuretana. Sabe-se que os materiais lignocelulósicos, como as fibras vegetais, são altamente higroscópicos, com o intuito de analisar a absorção de água de compósitos poliméricos a base de resina de óleo de mamona reforçado com fibras do bagaço de cana-de-açúcar, foram realizados testes de inchamento e absorção de água. Corpos de prova com quantidades diferentes de fibras foram adicionadas (10, 20 e $30 \%$ em volume) a matriz. O ensaio de inchamento foi realizado segundo NBR 14810. Pode-se perceber que não existe uma relação direta entre a absorção e fração de fibras nos compósitos, o que demonstra bom cobrimento das fibras pela matriz.
\end{abstract}

\section{INTRODUÇÃO}

O Brasil é um dos maiores produtores de cana-de-açúcar (NEOMONDO, 2018), e essa grande produção gera uma alta quantidade de rejeitos, diante disso, trabalho buscou suprir um dos desafios ambientais da indústria da cana-de-açúcar que é conseguir um destino de maior valor agregado para o seu principal subproduto, o bagaço. $\mathrm{O}$ crescimento da atividade industrial trouxe graves problemas ambientais, dessa forma, surge o desenvolvimento sustentável, que busca práticas ambientalmente corretas, a fim de minimizar os danos ao meio ambiente.

As fibras naturais têm ganhado a atenção de empresas e estudos científicos, pois seu uso como matéria prima resulta em produtos que geram menor impacto ao meio ambiente (ALVES, et. al, 2010), (JOHN \& THOMAS, 2008). 


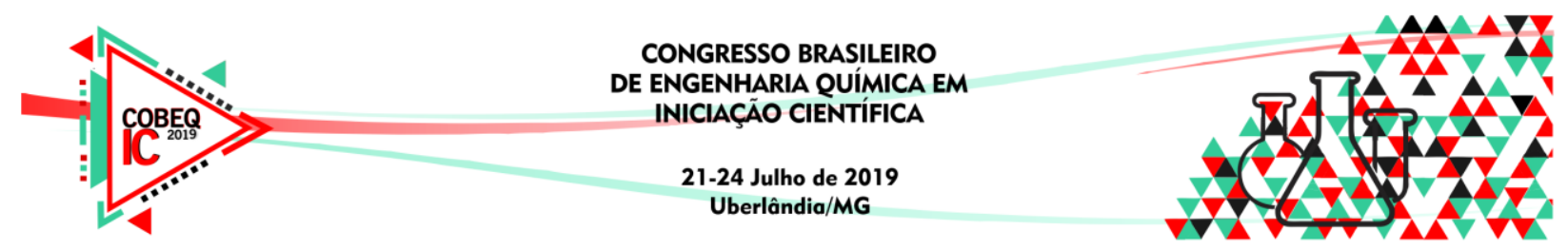

Quando comparadas às sintéticas, as fibras naturais apresentam algumas vantagens: são recicláveis, biodegradáveis, não são tóxicas, apresentam baixo custo, isolamento térmico e melhores propriedades mecânicas, como a resistência à tração e o módulo de elasticidade (FERNANDES et al., 2013).

Os constituintes químicos das fibras naturais são determinantes nas propriedades finais do compósito, pois afetam as propriedades físicas, mecânicas e térmicas dos materiais quando usadas como reforço. Porém, as aplicações de compósitos reforçados com fibras vegetais ainda não são expressivas, isso pode ocorrer pela fraca ligação entre a fibra e o polímero, devido à natureza hidrofílica da fibra e hidrofóbica do polímero. A interação da fibra com o polímero pode ser melhorada com tratamentos físicos e químicos (LALIT et al., 2018).

A matriz polimérica utilizada no trabalho foi a poliuretana de óleo vegetal de mamona. Essa matriz polimérica foi utilizada como uma alternativa para obtenção compósitos poliméricos reforçados com fibras naturais, visando obter compósitos totalmente ecológicos.

Segundo o estudo realizado por CALEGARI et al. (2017) em relação à resistência à tração, a poliuretana apresenta resistência muito baixa quando comparada ao poliéster, porém ao adicionar reforços à matriz, o poliéster torna-se menos resistente e a poliuretana mais resistente. Quanto à resistência ao impacto, a poliuretano apresenta resistência superior ao poliéster, tendo a capacidade de absorver mais energia durante da quebra (CALEGARI et al., 2017). O presente trabalho tem como objetivo analisar a absorção de água presente no compósito do bagaço de cana de açúcar com óleo de mamona.

\section{MATERIAIS E MÉTODOS}

Para preparação dos compósitos foi utilizado bagaço de cana de açúcar proveniente de uma usina da produção de açúcar, situada na cidade de Campos dos Goytacazes-RJ, a resina polimérica utilizada foi a poliuretana proveniente do óleo de mamona fornecida comercialmente pela empresa Quimisul. Depois de seco o bagaço de cana utilizado foi moído em moinho de facas até atingir tamanho variando de 6,5 a $8 \mathrm{~mm}$ de comprimento. Para limpeza da superfície das fibras do bagaço foi deixado de molho em uma solução de cloro de concentração $0,14 \mathrm{~mol} / \mathrm{L}$ durante 12 horas. Em seguida, o bagaço foi lavado em água destilada a $100^{\circ} \mathrm{C}$ e seco em uma estufa por 24 horas a $60^{\circ} \mathrm{C}$. 


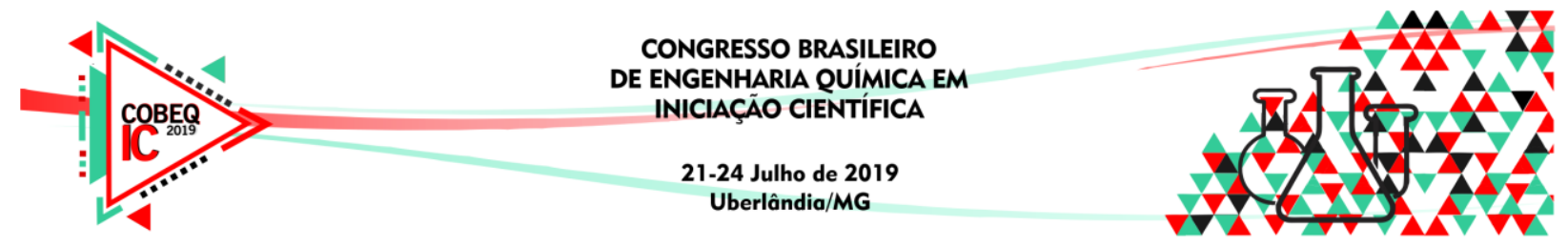

$\mathrm{Na}$ preparação dos compósitos as fibras foram misturadas manualmente na resina quando esta apresentava-se em estado fluido e depois vertidas em um molde metálico, as fibras não foram alinhadas em nenhuma orientação preferencial. Os compósitos tiveram o processo de cura realizado sob pressão de $100 \mathrm{~Pa}$ em uma prensa hidráulica, por 36 horas. Quantidades diferentes de fibras foram utilizadas na confecção dos compósitos, 0, 10, 20, 30\% em volume de fibra. Ao analisar as propriedades foram realizados de inchamento e absorção d'água conforme a norma NBR 14810 (ABNT, 2013).

\section{RESULTADO E DISCUSSÃO}

Os compósitos produzidos com as diferentes proporções de fibras estão apresentados na Figura 1.

Figura 1: Corpos de prova de compósito de óleo de mamona reforçados com bagaço de cana de açúcar.

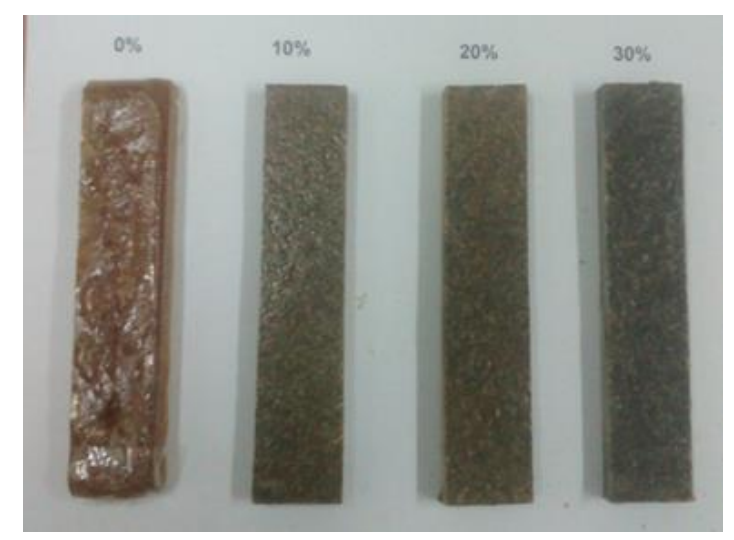

Através da foto apresentada na Figura 1 pode-se observar que os compósitos reforçados por fibras apresentam sua superfície mais regular do que o polímero (0\%), este aspecto está relacionado à interferência das fibras no processo de cura dos compósitos.

Na Tabela 1 estão dispostos os resultados dos ensaios de inchamento e absorção d'agua. 


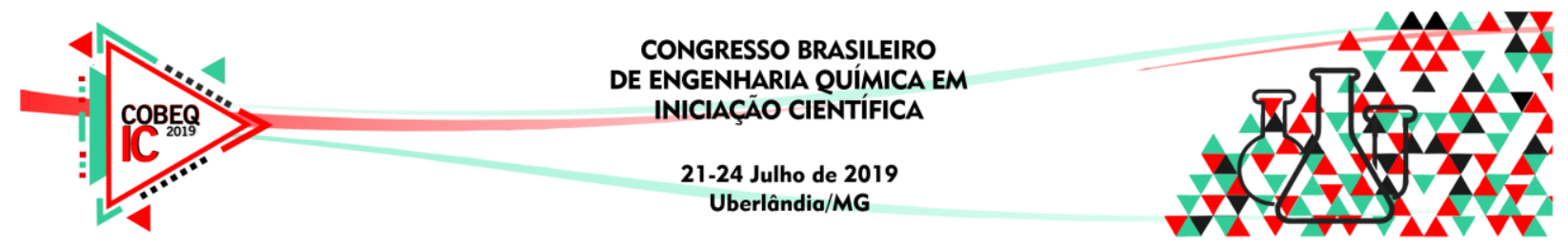

Tabela 1 - Resultado do ensaio de inchamento

\begin{tabular}{|c|c|c|c|c|}
\hline & \multicolumn{2}{|c|}{ 2 horas } & \multicolumn{2}{c|}{24 horas } \\
\hline \hline $\begin{array}{c}\text { Volume de } \\
\text { fibras (\%) }\end{array}$ & Média (\%) & Desvio (\%) & Média (\%) & Desvio (\%) \\
\hline \hline $0 \%$ & 0,1 & $\pm 0,10$ & 0,3 & $\pm 0,07$ \\
\hline $10 \%$ & 0,2 & $\pm 0,09$ & 0,9 & $\pm 0,10$ \\
\hline $20 \%$ & 0,3 & $\pm 1,00$ & 1,0 & $\pm 0,01$ \\
\hline $30 \%$ & 0,5 & $\pm 0,01$ & 1,0 & $\pm 0,03$ \\
\hline
\end{tabular}

Nota-se que com o aumento da concentração de fibras nos compósitos, houve um maior inchamento nos materiais. A baixa resistência à absorção das fibras, deve-se principalmente à presença dos grupos polares que atraem as moléculas de água através de pontes de hidrogênio, esse fenômeno resulta em um inchaço das fibras (KHALIL, et al., 2007).

Com o aumento da fração de fibras, nota-se o aumento da absorção de água. Nos corpos de prova de $0 \%$ houve um inchamento de $0,1 \%$ em 2 horas e $0,3 \%$ em 24 horas. Foi a menor absorção dentre todos corpos de prova. Os corpos de provas de $10 \%$ apresentaram absorção de $0,2 \%$ em 2 horas e $0,9 \%$ em 24 horas.

Os corpos de prova de $20 \%$ e $30 \%$ tiveram uma maior absorção de água, isso se dá pela natureza altamente hidrofílica da fibra de cana de açúcar, devido ao grupo hidroxila livre presente nas estruturas da celulose e lignina (ISMAIL, et al., 2003). Na Tabela 2 são apresentados os resultados do ensaio de absorção de água.

Tabela 2 - Absorção de Água dos compósitos poliméricos reforçado com fibra de cana de açúcar

\begin{tabular}{|c|c|c|c|c|}
\hline $\begin{array}{c}\text { Volume de } \\
\text { fibras (\%) }\end{array}$ & Média & Desvio & Média & Desvio \\
\hline $0 \%$ & 0,2 & $\pm 0,10$ & 0,3 & $\pm 0,10$ \\
\hline $10 \%$ & 0,05 & $\pm 0,02$ & 1,0 & $\pm 0,03$ \\
\hline $20 \%$ & 0,1 & $\pm 0,01$ & 1,8 & $\pm 1,60$ \\
\hline $30 \%$ & 0,1 & $\pm 0,02$ & 1,6 & $\pm 0,04$ \\
\hline
\end{tabular}




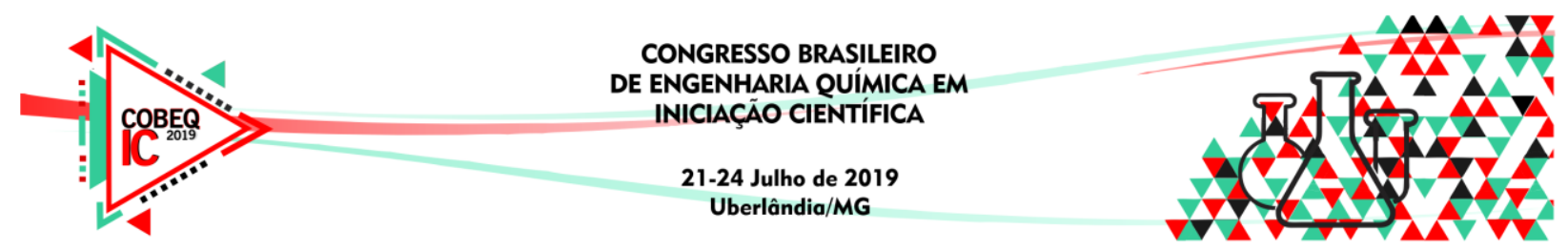

A absorção de água teve aumento com a evolução do tempo de imersão e também com o aumento da quantidade de fibra por volume. No entanto este aumento é estatisticamente insignificativo, o que ressalta o bom cobrimento das fibras pela resina polimérica, viabilizando assim a utilização destes compósitos mesmo em ambientes úmidos.

\section{CONCLUSÃO}

Com o aumento da quantidade de fibras elevou-se a absorção de água, mesmo que para patamares estatisticamente insignificantes, os corpos de prova com maior absorção de água, foram os de $20 \%$, com $0,3 \%$ de absorção, e 30\%, com 0,5\% de absorção, resultando em uma baixa absorção em comparação ao ganho obtido em resistência mecânica. Os polímeros produzidos unicamente com resina obtiveram a menor quantidade de água absorvidas.

\section{REFERÊNCIAS}

ABNT (2013) Associação Brasileira de Normas Técnicas. NBR 14810.

ALVES, C.; FERRÃO, P. M. C.; SILVA, A. J.; REIS, L. G.; FREITAS, M.; RODRIGUES, L. B.; ALVES, D. E .Ecodesign of automotive componentes making use of natural jute fiber composites. Journal of Cleaner Production, Portugal, v.18, n.4, p.313- 327, mar. 2010.

CALEGARI, E. P.; PORTO, J. S.; ANGRIZANI, C. C.; OLIVEIRA, B. F.; DUARTE, L. C; AMICO S. C. Reuse of waste paper nad rice hulls as filler in polymeric matrix composites. Revista Matéria, Rio de Janeiro, v. 22, n. 2, jul. 2017.

FERNANDES, E. M.; MANO, J. F.; REIS, R. L. Hybrid cork - polymer composites containing sisal fibre: Morphology, effect of the fibre treatment on the mechanical properties and tensile failure prediction. Composite Structures, Portugal, v.105, p.153-162, nov. 2013.

ISMAIL, H.; HONG, H. B.; PING, C. Y; KHALIL, H. P. S. A. Polypropylene/Silica/Rice Husk Ash Hybrid Composites: A Study on the Mechanical, Water Absorption and Morphological Properties. Journal of Thermoplastic Composite Materials, Malásia, v. 16, n. 2, p. 121-137, mar. 2003.

JOHN, M. J.; THOMAS, S. Biofibres and biocomposites. Carbohydrate Polymers, Índia, v.71, n. 3, p. 343- 364, fev. 2008.

KHALIL, H. P. S. A.; HANILDA, S.; KANG, C. W. Agro-hybrid Composite: The Effects on Mechanical and Physical Properties of Oil Palm Fiber (EFB)/Glass Hybrid Reinforced Polyester Composites. Journal of Reinforced Plastics and Composites, Malásia, v.26, n.2, jan. 2007. 


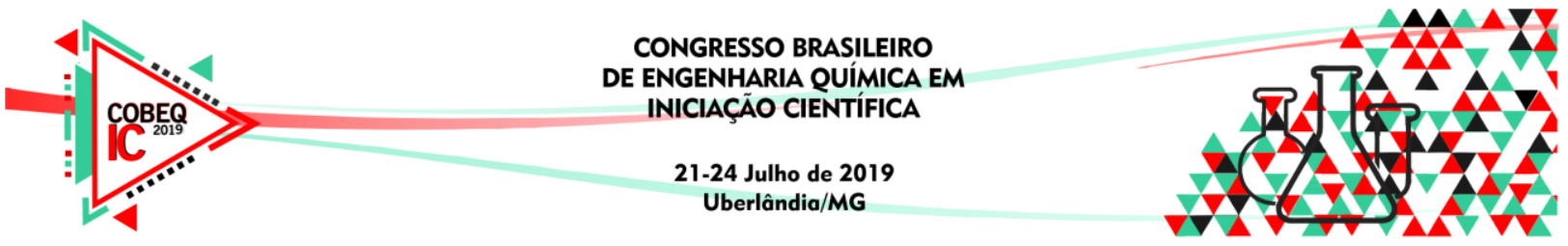

LALIT, R.; MAYANK P.; ANKUR, K. Natural fibers and biopolymers characterization: A future potential composite material. Journal of Mechanical Engineering, Bratislava, v.68, n.1, p. 33-50, abr. 2018.

NEOMONDO, Brasil é o maior produtor mundial de cana-de-açúcar, Estadão, 21 de junho de 2018. Disponível em: < http://www.neomondo.org.br/2018/06/21/brasil-e-o-maior-produtormundial-de-cana-de-acucar/>. Acesso dia: 13 de março de 2019. 